\title{
LA TRAYECTORIA DEL DESARROLLO SOCIAL PRECOLOMBINO EN EL SUR DE MANABÍ
}

Alexander J. Martin ${ }^{l}$

Catherine Lara ${ }^{2}$

\begin{abstract}
Resumen
Este artículo reconstruye la larga trayectoria de desarrollo precolombino de las poblaciones del Parque Nacional Machalilla, sur de Manabí, Ecuador, desde tiempos formativos hasta la llegada de los españoles. Los resultados de una prospección sistemática de cobertura total indican que estas poblaciones retuvieron niveles demográficos bajos y poca evidencia de estratificación social hasta los finales del Desarrollo Regional (ca. 700 d.C.). En cambio, la evidencia arqueológica sugiere que el subsiguiente período de Integración (700-1532 d.C.) presenció un salto demográfico considerable, una alta concertación poblacional en el poblado de Machalilla, evidencia más marcada de estratificación social y el desarrollo de comunidades supra-locales.
\end{abstract}

\begin{abstract}
This article reconstructs the long path of pre-Columbian development of the populations of the Machalilla Nacional Park, in Southern Manabi, Ecuador, from the formative period up until the arrival of the Spanish. The results of a systematic investigation of complete coverage indicates that these populations retained low demographic levels and little evidence of social stratification until the end of the Regional Development (cerca. 700 a.C.). On the other hand, the archeological evidence suggests that the following Period of Integration (700- 1532 a.C.) presided a considerable demographic leap, a high concentration of inhabitants at the Machalilla settlement, evidence which is more marked by social stratification and the development of supra-local communities.
\end{abstract}

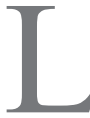

as culturas precolombinas del litoral ecuatoriano ocuparon un lugar exclusivo dentro de la producción especializada de bienes exóticos elaborados a partir de concha Spondylus, debido a la escasa disponibilidad de este bivalvo - al cual las poblaciones de la costa ecuatoriana tenían acceso-, así como a la existencia de mercados regionales ubicados en el actual territorio peruano, han sido reconocidos como grandes consumidores de estos bienes suntuarios (Marcos, 1995; Martín, 2007; Paulsen, 1974; Pillsbury, 1996; Zeidler, 1991). Según las fuentes etnohistóricas, en la época de la llegada de los españoles, la concha Spondylus revestía un gran valor ritual y tenía una

1 ArqueólogoUniversidad de Pittsburgh

2 Arqueóloga por la PUCE 
fuerte importancia simbólica en las comunidades de los Andes Centrales de Perú, a pesar de su escasez en esta región debido a las bajas temperaturas de sus aguas (Abbot, 1974; Keen, 1971; Murra, 1982; Olsson, 1961).

Los relatos históricos indican que el intercambio de objetos de Spondylus - el cual se presentaba en forma de pequeñas cuentas llamadas «chaquiras» y otros objetos decorativos - se expandió en parte desde un centro político conocido como Çalangome, ubicado en el actual Parque Nacional Machalilla, en el sur de Manabí (Pizarro 1844a [1527], 1844b [1571]). Las poblaciones indígenas que residían en el área eran conocidas bajo el nombre de «Manteños». Las fuentes etnohistóricas señalan que dentro del territorio manteño, la elaboración de ornamentas de concha tuvo lugar en cuatro asentamientos precolombinos, denominados Çalangome, Tuzco, Çalango y Seracapez. Los investigadores que trabajan en el área han ubicado a estos asentamientos de forma tentativa, localizándolos en las aproximaciones de los poblados actuales de Agua Blanca, Machalilla, Salango y López Viejo respectivamente, representados en la Figura 1 (Silva, 1984; Currie, 1995a, 1995b).

La demanda peruana por el molusco habría sido impulsada desde los centros políticos del norte de los Andes Centrales, incrementándose en forma considerable después de Moche V (ca. A.D. 600), y perpetuándose durante las ocupaciones Sicán y Chimú (CordyCollins, 1990; Martín, 2007; Pillsbury, 1996; Shimada, 1994). Los académicos que trabajan en la costa ecuatoriana han ligado directamente el intercambio de este producto al desarrollo de estructuras jerárquicas en el sur de Manabí, proponiendo distintos mecanismos para explicar este desarrollo. A manera de ejemplo, Muse (1989) sugiere que la sociedad manteña estaba tan especializada en la producción de bienes destinados al intercambio regional, que se vio obligada a intercambiar algunos de los bienes exóticos que elaboraba por maíz, producido por sus vecinos sureños Huancavilcas (ubicados en la actual provincia de Guayas, Figura 2), con la finalidad de asegurar su propia subsistencia. Muse describe a la sociedad manteña como seguidora de una trayectoria de desarrollo distinta en comparación con las demás sociedades de la zona, cuyo trasfondo económico estuvo conformado por la producción de bienes de intercambio que las condujeron a depender de relaciones simbióticas. No todos los investigadores concuerdan en que la industria de Spondylus haya ocupado un papel central en la economía local manteña, aunque algunos subrayan que el intercambio de este recurso pudo haber acelerado el desarrollo social, al estructurar las instituciones políticas. Zeidler (1991) por ejemplo, constata que el control de este bien pudo haber contribuido a institucionalizar el estatus de los «grandes hombres» (big men), quienes controlaban su comercio desde épocas tan tempranas como Valdivia (3500-1500 d.C.); Marcos por su parte (1995), argumenta que el incremento de Spondylus durante los años más cálidos fomentó la desigualdad social al reafirmar el conocimiento shamánico de aquellos individuos que entendían la relación de esta coyuntura con la llegada del fenómeno de "El Niño". La importancia y la amplia distribución de la concha, muchas veces atribuida al movimiento y al control de este recurso, llevó a varios investigadores que trabajaron en la región a proponer una amplia categorización de las diferentes poblaciones de la costa ecuatoriana, generalmente designadas bajo el nombre de «Liga de Mercaderes Manteños» (Marcos, 1977/78, 1995; Norton, 1986). 
Como vemos, las sociedades del sur de Manabí son a menudo presentadas como altamente dependientes del comercio de la concha Spondylus, propuesta como la base de su florecimiento sociopolítico y subsistencia. Sin embargo, la mayoría de estas propuestas no han sido comprobadas empíricamente, por lo cual la relevancia de esta industria frente a los procesos de desarrollo social ha tendido a ser asumida antes que comprobada. En este sentido, nuestro estudio en el sur de Manabí ofrece una excelente oportunidad de fortalecer los conocimientos existentes sobre la naturaleza del desarrollo social de la zona, especialmente en lo que se refiere al papel del intercambio a nivel regional. Reconstruir las trayectorias de desarrollo de estas poblaciones-así como los orígenes y modalidades de este proceso - ofrece una idea más precisa sobre él, más allá de sus manifestaciones sociales y políticas, contribuyendo a la vez a aclarar la naturaleza de la producción prehistórica de bienes de exportación, y su papel en el desarrollo de la estratificación social.

\section{Métodos y área de estudio}

Con la finalidad de explorar la relación existente entre la complejidad social y el surgimiento de mercados regionales externos, fue preciso recolectar datos que permitieran generar diversos tipos de información en distintos lugares, y a una escala regional. Fue particularmente importante reconstruir la naturaleza de los asentamientos de la región en distintas épocas. Con este propósito en mente, una prospección sistemática e intensiva fue llevada a cabo en un área de aproximadamente cien kilómetros cuadrados (Figura 1). La prospección se ubicó precisamente en la zona en que las fuentes etnohistóricas mencionan la presencia de sociedades políticamente estratificadas e involucradas en la elaboración de productos de concha durante la llegada de los españoles (Currie, 1995a, 1995b; Pizarro, 1844a [1527], 1844b [1571]; Silva, 1984). Otro criterio para la ubicación de nuestra zona de estudio fue la presencia en el área de prospección de dos de los cuatro asentamientos precolombinos conocidos como productores de objetos de Spondylus: Machalilla (probablemente Tuzco), Agua Blanca (probablemente Çalangome) y sus respectivas inmediaciones (Currie, 1995a, 1995b; Mester, 1990; Silva, 1984).

Esta zona fue completamente cubierta por equipos de prospección de manera sistemática. Tan pronto una concentración de material era detectada en un área, ésta era dividida en lotes de una hectárea aproximadamente. Al centro de cada uno de estos lotes, una recolección sistemática de artefactos era llevada a cabo en un área determinada, aplicando la técnica de «cadena de perro» (dog leash technique), con la finalidad de determinar los cambios de densidades y las variaciones de artefactos entre los diferentes lotes. Las muestras recuperadas presentaron cantidades considerables de cerámica, lítica y concha. El material cerámico fue luego clasificado en diversas fases cronológicas con el objetivo de reconstruir la evolución de los patrones de asentamiento. La densidad y las variaciones entre los lotes de recolección sirvieron como base para las reconstrucciones de los patrones de asentamiento y demográficos presentados a continuación, constituyéndose además como la fuente principal de información sobre la distribución y naturaleza de la producción de objetos de concha a través del territorio. Muchas concentraciones de conchas fueron además claramente identificadas en la superficie de nuestra zona de estudio. 
La prospección inicial reveló la presencia de cantidades considerables de fragmentos trabajados de concha Spondylus dentro de estas concentraciones, por lo cual éstas se configuraron como evidencia material importante de las actividades de trabajo de concha. Tan pronto una de estas concentraciones era localizada, una recolección sistemática adicional era llevada a cabo en ella. Hace casi tres décadas ya, Sanders, Parson, y Santley (1979: 51) reconocieron que las densidades y proporciones de material arqueológico en la superficie son altamente representativas de las variaciones del material del subsuelo, en particular a escalas regionales. Más recientemente, autores como Drennan (2006), Peterson (2006), y Murillo (2009) han reiterado el alto nivel de correspondencia entre las proporciones de materiales en la superficie y debajo de ésta en diversas localidades a lo largo del mundo. Si bien en escalas muy pequeñas (como a nivel de unidades domésticas o de excavación), procesos de formación más localizados puedan a veces interferir con esta correspondencia, la amplia superficie de nuestra zona de estudio aumenta el grado de representatividad de las colecciones de superficie en relación al material arqueológico bajo tierra.

La metodología aquí utilizada en la definición de cantidades poblacionales absolutas se origina en las técnicas empleadas para el análisis de patrones de asentamiento en el valle de México (Sanders, Parsons y Santley, 1979: 20-30), posteriormente desarrolladas para el análisis de los datos obtenidos en el valle de Oaxaca (Blanton et al., 1982; Kowalewski et al., 1989). Luego de subsiguientes refinamientos por Drennan (2006) y Drennan et al. (2003a), este acercamiento metodológico de inferencias demográficas es el más completo actualmente disponible para recrear estimaciones poblacionales a escala regional (Drennan et al., 2003a, 2003b; Fish y Kowalewski, 1990). Su aplicación conoció múltiples logros en la estimación de poblaciones regionales de varias sociedades prehispánicas del Área Intermedia y del mundo, tal como lo manifiestan los estudios de Cuellar (2006) y Delgado (2002) en el Ecuador, Drennan (2006) y Langebaek (1995) en Colombia, Haller (2008) en Panamá, Murillo (2009) en Costa Rica, Kim (2005) en Corea del Sur, Drennan et al. (2003a) y Peterson (2006) en China, etc. Las investigaciones de Martín (2009a), Drennan (2006), Peterson y Drennan (2005) ofrecen descripciones más detalladas de esta metodología de prospección, de sus clasificaciones cronológicas y tipológicas, así como de las reconstrucciones demográficas aquí presentadas. Por otra parte, Drennan et al. (2003a, 2003b) desarrollaron descripciones metodológicas más profundizadas del enfoque aquí empleado. Todos los datos cerámicos, líticos, y malacológicos obtenidos durante la prospección, tanto como su distribución espacial, pueden ser obtenidos en la Base de Datos de la Arqueología de América Latina ubicada en la página http://www.pitt.edu/ laad/.

\section{La trayectoria de desarrollo social del sur de Manabí}

\section{Período Formativo (3300-300 a.C.)}

Empezaremos por una exploración de los asentamientos de este período a partir de la información recuperada en los lotes que evidenciaron la presencia de cerámica formativa (Figura 3, mitad superior). El patrón más evidente que se puede distinguir aquí es quizá 
la gran cantidad de lotes con pequeñas muestras aisladas de material que se reparten a lo largo de toda el área de estudio. Estos pequeños lotes presentan una superficie de un poco menos de una media hectárea, y tienden a ubicarse en las planicies elevadas de las diversas lomas esparcidas en toda el área prospectada. Esta distribución dispersa del patrón de asentamiento coincide con la distribución actual de las fincas del sur de Manabí, en donde la casa de una sola familia - generalmente construida de caña—se aprovecha de la topografía natural y asegura su subsistencia directamente de sus tierras a partir de un sistema de agricultura extensiva (Rudolf, 1999: 44-46; Yépez, 2007: 616). En escenarios precolombinos - pero también apropiado para la actualidad-Drennan (1988) sugiere que esta organización de asentamientos dispersos está relacionada con formas de producción en donde cada unidad familiar controla su producción independientemente. Las unidades domésticas se radican directamente en las tierras que explotan, con el objetivo de minimizar la cantidad de tiempo utilizado en caminar hasta sus campos de cultivo, maximizando así la eficiencia laboral de toda la unidad familiar. En este sentido, la organización de la producción es percibida como la causa principal de este patrón de asentamiento disperso.

Se puede además observar una pequeña agrupación de lotes en los alrededores del actual poblado de Machalilla. Si tomamos en cuenta las densidades de material de las diferentes muestras recuperadas en cada lote (Figura 3, mitad inferior), notamos que esta concentración se presenta como el área más densa de toda la zona prospectada. Este fenómeno parece indicar que, pese a la dispersión de las unidades domésticas a lo largo de la región, esta localidad costera parece también haber atraído a una cantidad importante de pobladores.

En términos de cifras demográficas absolutas, la población regional de esta época era muy baja. Las cantidades de material cerámico formativo evidenciadas en el área de estudio sugieren que menos de cien personas residieron en el área prospectada en cualquier momento dado del período Formativo. A pesar de sobresalir como el punto más denso de ocupación, la evidencia cerámica de Machalilla sólo da cuenta de veinticinco a cincuenta personas residentes en este lugar durante cualquier momento dado del Formativo. Desde este punto de vista, es perfectamente legítimo caracterizar a este asentamiento como un pequeño caserío en donde unas pocas familias residían en relativa cercanía. En el resto del área prospectada, las densidades de fragmentos cerámicos son tan bajas que representan probablemente ocupaciones aisladas y temporales de unidades domésticas que al parecer no duraron más de una generación cada una. Vale recalcar aquí que el índice de densidad de áreas empleado para llegar a estas inferencias numéricas se basa en el promedio del material formativo depositado en el área por siglo (Drennan, 2003a).

Así, para la reconstrucción de cantidades demográficas, se multiplicó primero la densidad de material cerámico de cada lote (por período) por el área del mismo con la finalidad de obtener un índice que tome en cuenta no sólo la densidad de material, sino también el área de cada lote. Con la intención de poder comparar los distintos periodos (ya que cada uno tiene duraciones distintas), esta cifra se dividió luego por el numero de siglos de cada periodo (treinta para el Formativo, once para el Desarrollo Regional, y siete para el período de Integración). Para establecer cantidades absolutas, se comparó finalmente este índice con el índice promedio de cantidades de desechos cerámicos de una unidad doméstica estándar (ver Martín, 2009a: 19-62 para una descripción detallada 
de este proceso). Como consecuencia, este índice provee esencialmente un acercamiento promedio de la ocupación formativa por siglo. Tomando en cuenta que el Formativo corresponde en realidad a un largo período de 3000 años, cuya población probablemente se incrementó con el paso del tiempo, es lógico pensar que durante las etapas más tempranas de esta secuencia cronológica, la población era menor a este promedio, pero mayor en sus últimos años.

La distribución de los asentamientos ofrece asimismo valiosas aproximaciones sobre las estrategias básicas de subsistencia desplegadas por la población regional. Por lo visto, la ubicación costanera de los asentamientos de Machalilla habría atraído a una cantidad de habitantes relativamente importante - al menos la mitad de la población del área. La ubicación privilegiada de Machalilla en las cercanías del océano-rico en recursos de tipo $r$ - es sin duda alguna la razón potencial más obvia para explicar la elección de las unidades domésticas que optaron por asentarse en esta localidad. En la literatura arqueológica, es comúnmente aceptado que la explotación de recursos marítimos de tipo $r$ desemboca en una relativa cercanía entre unidades domésticas a nivel de sus patrones de asentamiento, contribuyendo así a una mayor interacción social y comunal (Akazawa, 1986; Moseley, 1975, 1992; Zvelebi, 1986). La explotación de recursos marítimos disminuye también la necesidad de dispersión doméstica — ocasionada por la tenencia de tierras - lo cual parece explicar el grado relativo de cercanía en la distribución espacial de las unidades domésticas de esta ubicación costanera. Desde luego, este patrón regional de asentamiento no excluye la explotación de recursos agrícolas o terrestres. Efectivamente, tierra adentro, las ocupaciones más dispersas, cuyo énfasis productivo se habría radicado más directamente en recursos terrestres, siguen representando una proporción sustancial de la población regional. No obstante, si bien las poblaciones del Formativo parecen haber sacado provecho de los recursos terrestres disponibles, fueron las estrategias de subsistencia marítimas las que parecen haber generado las fuerzas centrípetas que empujaron a los pobladores a concentrarse en lo que tradicionalmente se conoce como una "comunidad local" pequeña (Peterson y Drennan, 2005).

Esta información pone de relieve un panorama más coherente del tipo de sociedad representado por la evidencia arqueológica del período Formativo aquí recuperada. La comunidad de Machalilla constituye el único sitio dentro del área de estudio en ofrecer índices de concentración poblacional substanciales. No obstante, en un pequeño caserío de cinco a diez familias, es muy poco probable que la concentración poblacional se diera por motivos políticos. La imagen de jefes poderosos movilizando a sus súbditos es poco apropiada en el caso de un pequeño caserío de unas pocas casas de caña, donde cualquier nivel de estratificación social dado se basaba probablemente en estructuras de parentesco. Por otro lado, una ubicación favorable en términos de estrategias marítimas de subsistencia explicaría de forma más razonable por qué unidades domésticas decidieron radicarse en asentamientos continuos y más concentrados en esta área.

Sin embargo, se puede explorar más detenidamente la posible influencia de incentivos ajenos a las prioridades locales de la comunidad - muchas veces llamadas formas «supra-locales» de organización social (Peterson y Drennan, 2005) — en la distribución de asentamientos. Estas configuraciones supra-locales de asentamientos son a menudo el resultado de fuerzas políticas que actúan sobre la elección de los lugares de residencia a nivel poblacional, e incentivan generalmente a los individuos a organizarse entre ellos 
en unidades cohesivas de interacción, visibles a escalas que sobrepasan la comunidad local tradicional. Peterson y Drennan observan que el suavizar progresivamente las representaciones de densidades cerámicas - representada por ejemplo en la parte inferior de la Figura 3 - es una forma útil de ver este tipo de formas supra-locales de organización social en los patrones de asentamiento. Conforme se suaviza progresivamente la representación de densidades cerámicas, los asentamientos periféricos más pequeños se agrupan con los más grandes y centrales. Las superficies suavizadas evidencian la existencia de diferentes distritos geográficos de interacción, en base a las propiedades intrínsecas de distribución de los asentamientos. Siguiendo esta lógica, la Figura 4 ilustra el rendimiento en perspectiva de la densidad cerámica formativa, suavizada mediante el uso del índice de distancia inversa elevado a las potencias $4,2,0.5$ y 0.25 . Tal como se lo puede apreciar, el resultado obtenido no permite hablar de múltiples distritos de interacción durante este período. Machalilla es el único asentamiento dominante en el territorio; como tal, se configura como el incentivo para su fusión con todo el resto de la ocupación regional, fenómeno visible a través del incremento progresivo del suavizado. Este fenómeno apuntala un posible escenario en el que las pequeñas unidades domésticas agrícolas del Formativo se distribuían originalmente en el territorio en base a sus intereses locales e individuales, sin verse afectadas por influencias sociales de escalas mayores.

En términos de inversión de arquitectura no-doméstica, el mejor ejemplo proviene probablemente del sitio de Salango, al sur de Manabí (Figura 1), situado a unos pocos kilómetros fuera de la zona de prospección, en donde Lunniss y sus colegas (2001, 2007, 416; Norton, Lunniss y Nayling, 1983) excavaron una casa ceremonial de caña que tenía como soporte principal una serie de pequeños postes de madera sin evidencia alguna de fundaciones de piedra trabajada o de arquitectura elaborada.

Este tipo de evidencia se compagina con formas simples e igualitarias a nivel de la organización social. A lo sumo, podría representar lo que se conoce comúnmente en la literatura especializada como una sociedad de «grandes hombres» (big man society) (Sahlins, 1963). De hecho, investigadores como Zeidler (1991) observan que ésta es la manera más apropiada de caracterizar al grado máximo de estratificación social alcanzado por las poblaciones formativas de Manabí. A lo largo de la costa ecuatoriana, ninguna evidencia clara de áreas de elaboración de objetos en concha Spondylus ha sido excavada de momento dentro de contextos formativos (Carter, 2008), aunque, hasta cierto punto, la presencia de cuentas en sitios ecuatorianos de este período atestigua la práctica de esta actividad por parte de poblaciones formativas. En este sentido, una pequeña industria local de elaboración de objetos destinados al consumo interno podría haber complementado el amplio abanico de recursos marítimos que convirtieron a la bahía de Machalilla en un asentamiento óptimo para las pocas unidades domésticas que ahí residían. No obstante, la ausencia de desarrollo sociopolítico en el área confirmaría ante todo que una pequeña industria destinada al consumo local no fue un poderoso catalizador de desarrollo social.

\section{Período de Desarrollo Regional (300 a.C. - 800 d.C)}

No se observan mayores cambios en el patrón de asentamiento del Período de Desarrollo Regional. En el área prospectada (Figura 5), la población regional se incrementa levemente pero continúa siendo de tamaño modesto, con unos pocos 
centenares de habitantes viviendo dentro de la zona de estudio para cualquier momento dado del período. El pequeño asentamiento de Machalilla sigue siendo la única comunidad claramente definida en todo el territorio, presentándose esta vez como una población de mayor tamaño, con un promedio de poco más de un centenar de habitantes. El resto de la población sigue viviendo de forma dispersa a lo largo de todo el territorio, en pequeñas unidades domésticas aisladas.

El patrón de asentamiento sugiere además que la subsistencia seguía basándose en los mismos elementos registrados para el Formativo. Mientras que un porcentaje relativamente alto de unidades domésticas siguió asentada tierra adentro, aprovechándose de recursos terrestres y de la agricultura extensiva; la mayoría de individuos se agrupó en los alrededores de la bahía de Machalilla, aparentemente con la intención de beneficiarse de los recursos que ésta ofrecía, explotados en grados mucho mayores que en el Formativo. Tal como se lo explicó más arriba, la utilización de recursos de tipo $r$ implica generalmente bajos costos de explotación, lo cual no sólo favorece un estilo de vida sedentario, sino también formas de asentamiento más compactas y concentradas. La literatura académica señala que este tipo de fenómenos no sólo fomenta la interacción social y comunal, sino que también estimula organizaciones sociales de tipos más complejos (Moseley, 1975; 1992). Desde esta perspectiva, las grandes cantidades de recursos marítimos disponibles en el entorno de los pobladores de Machalilla pueden explicar no sólo la elevada concentración poblacional de este asentamiento desde épocas formativas, sino también el moderado incremento demográfico y la creciente densidad ocupacional ahí registrados.

No descartamos que el incremento poblacional observado en Machalilla haya sido el resultado de factores no relacionados a un acceso óptimo a recursos concentrados. El surgimiento de elites políticas es generalmente citado como un catalizador potencial para el desarrollo de la complejidad social, y de un subsiguiente incremento de la concentración poblacional, basado en la necesidad social de residir cerca de las elites (a manera de ejemplo, ver Blanton et al., 1996; Earle, 1997; Vaughn, 2006). Durante el período de Desarrollo Regional, no cabe duda que esta comunidad alcanzó un límite demográfico lo suficientemente amplio (treinta familias en promedio) como para evocar la hipótesis de al menos algún tipo de estratificación social. En una comunidad de poco más de un centenar de personas, la interacción diaria requeriría al menos cierto nivel de jerarquización social o de control político. No obstante, esta escala demográfica aún no se compagina con el tipo de comunidad local en que se puede asumir la presencia de poderosas entidades políticas. Si examinamos la forma en que esta comunidad se integró con sus alrededores (Figura 5), observamos una vez más que pequeñas unidades domésticas aisladas rodean un solo poblado de dimensiones modestas (Machalilla). En términos de evidencia de organización social basada en escalas mayores a la comunidad local, el patrón de asentamiento también evidencia una ausencia de organización supra-local. El suavizado progresivo de la distribución de densidades cerámicas para el Desarrollo Regional (Figura 6) demuestra que la jerarquía simple en el patrón de asentamiento provoca la fusión de toda la ocupación regional con Machalilla. Una vez más, la evidencia de asentamientos no provee ningún tipo de evidencia que permitiera apoyar alguna forma de integración orientada hacia la organización de poblaciones en patrones supra-locales.

Una forma adicional de explorar el grado de estratificación social dentro de los estudios regionales es la definición de posibles diferencias de estatus entre el registro material de los 
diversos asentamientos. Si la comunidad de Machalilla demostrara una mayor evidencia de cerámica de alto estatus, ésta podría señalar la presencia de élites o de algún tipo de concentración de riquezas. La comparación de cerámica para investigar la presencia de individuos de alto estatus en distintos asentamientos ha sido tradicionalmente llevada a cabo en base a dos ejes: la presencia de cerámica más fina por un lado, y la evidencia de actividades festivas por otro. La idea de cerámica más fina como indicadora de la presencia de élites se basa en el supuesto de que, en igualdad de condiciones, este tipo de material requiere una mayor elaboración, siendo así su producción más "costosa" a nivel social que la de cerámicas de tipo más burdo. Por otra parte, la evidencia de cerámica de actividades festivas (tradicionalmente medida en base a la cantidad de vajilla para servir presente dentro de los componentes cerámicos), es a menudo usada para indicar la presencia de excedentes de producción, y por ende, de una concentración mayor de riquezas (a manera de ejemplo, ver Boada, 2007).

Con la finalidad de llevar a cabo una comparación de la evidencia cerámica de Machalilla con el resto del área de estudio, las muestras de los lotes pertenecientes a esta comunidad fueron separadas de acuerdo a la estrategia empleada por Peterson y Drennan (2005). Éstos proponen que para evidenciar los límites de las comunidades locales, es preciso escoger una línea de contorno topográfico en las perspectivas de densidades cerámicas no-suavizadas que incluyan el pico de densidad cerámica utilizado para definir a esa comunidad. En base a esta propuesta, las delimitaciones del asentamiento de Machalilla para el Desarrollo Regional, así como los lotes que aparecen dentro de estos límites, fueron representados en la Figura 5. Los lotes incluidos dentro de estos límites fueron agrupados con el objetivo de inferir las proporciones de los diferentes tipos cerámicos de todo el asentamiento de Machalilla en sí. Los demás lotes fueron luego sumados para la obtención de promedios proporcionales para toda la ocupación de unidades domésticas aisladas en el resto del área. Los márgenes de error estadístico de estas proporciones fueron calculados usando una fórmula de muestreo en agrupación (cluster sampling) (Drennan, 1996: 247-251).

La Figura 7 utiliza tres criterios diferentes para medir la presencia de élites. En el caso de la cerámica fina, la Figura 7a ilustra la proporción de fragmentos cerámicos elaborados sobre el total de fragmentos cerámicos recuperados, mientras que la Figura $7 \mathrm{~b}$ grafica la proporción de fragmentos cerámicos altamente pulidos sobre el total de fragmentos recuperados. Adicionalmente, la Figura 7c representa la proporción de vajilla para servir dentro del componente cerámico integral. En los tres casos, se evidencia un mismo patrón: Machalilla da cuenta de proporciones más altas de cerámica fina y de vajilla para servir que las ocupaciones campesinas aisladas (aunque el margen de errorrelativamente alto - sugiere un nivel de confianza moderado en las diferencias observadas en estas proporciones). Este fenómeno apoya la hipótesis de al menos un tipo sencillo de estratificación social en el área de estudio para el Periodo de Desarrollo Regional.

Es de suma importancia aquí establecer una distinción entre formas de estratificación social en las cuales las diferencias de estatus son institucionalizadas desde el nacimiento (esto es, sociedades de estatus «adscrito»), y aquellas menos jerarquizadas en que el estatus requiere ser «adquirido» durante la vida del individuo a partir de una matriz social básicamente igualitaria (llamada sociedad de "grandes hombres") (Fried, 1967). La relevancia de esta distinción radica en que, en los contextos protagonizados por «grandes 
hombres», el nivel de control político de la élite es tan bajo que para poder ejercer algún tipo de coerción social, el "gran hombre" debe esencialmente trabajar a pérdida. Por otro lado, los escenarios en que la posición de élite está institucionalizada y su duración rebasa el período de vida de los individuos, permiten una coerción social mucho mayor. Precisamente, este último contexto es a menudo asociado a los tipos de presiones sociales que influyen de manera considerable en la selección de asentamientos.

Excavaciones horizontales llevadas a cabo previamente en el sur de Manabí dan cuenta de una ausencia generalizada de estratificación entre las poblaciones del Desarrollo Regional, lo cual incluye escasas diferenciaciones en los entierros, inversión modesta en estructuras no-domésticas, y evidencia mínima - por no decir nula-de consumo conspicuo por parte de la élite, tal como el que Stemper evidenció en el área del río Daule, en Guayas (a manera de ejemplo, ver Harris et al. 2004; Reitz y Masucci 2004). La evidencia extraída aquí de los patrones de asentamiento sugiere niveles muy marginales de complejidad social o de estratificación para toda el área, con cifras demográficas absolutas bajas, una jerarquía de asentamiento simple (de dos niveles), y una ausencia generalizada de organización supra-local. La única comunidad local que aparece en el paisaje es un pequeño poblado ubicado precisamente en la misma área en que los individuos tendían a concentrarse en el período formativo-y por motivos de subsistencia. Aunque las comparaciones de material cerámico parecen indicar que para la época del Desarrollo Regional, Machalilla poseía efectivamente al menos algún grado de diferenciación social en comparación con las unidades domésticas aisladas, hay muy poca o ninguna evidencia que sugeriría formas más institucionalizadas de liderazgo social en lo que se refiere al patrón de asentamiento. Desde este punto de vista, la explicación más probable al énfasis demográfico persistente y creciente registrado en el asentamiento de Machalilla sigue siendo su cercanía al océano y sus recursos. El que este incremento poblacional esté relacionado con el surgimiento de algún grado de diferenciación de estatus entre sus habitantes es perfectamente razonable, pero es poco probable que en una sociedad local tan pequeña como ésta, tal diferenciación haya sido muy pronunciada.

Las excavaciones localizadas llevadas a cabo en la costa ecuatoriana para gran parte del período de Desarrollo Regional no han ofrecido mayores evidencias de trabajo de concha (Carter, 2008: 137-140). Dos excepciones notorias son los sitios del Valle de El Azúcar, ubicados en la actual provincia de Guayas (Masucci, 1995; Reitz y Masucci, 2004) y la fase de la ocupación Bahía del sitio de Río Chico (Harris et al., 2004). En base a los componentes fáunicos heterogéneos ahí registrados, ambos sitios han sido clasificados como áreas de trabajo mixtas en que unidades domésticas se consagraron parcialmente a la producción de bienes, llevando a cabo también otras labores relacionadas a la subsistencia (Harris et al., 2004; Martín, 2009b; Masucci, 1995). Tomando en cuenta que las poblaciones prehistóricas ecuatorianas estuvieron utilizando objetos de concha Spondylus en sus componentes locales durante un amplio período, es muy probable que la evidencia marginal de trabajo de concha registrada en el Ecuador para el período de Desarrollo Regional represente más que nada una producción destinada al consumo interno.

Una vez más, la evidencia relativamente marginal del trabajo de concha durante el período de Desarrollo Regional, en conjunto con la ausencia general de un grado sustancial de estratificación social dentro del área, sugiere que el tipo de manufactura de concha 
que se llevó a cabo durante este período no fue un catalizador poderoso de complejidad sociopolítica, ya sea porque la cantidad de consumidores locales era pequeña, o porque el consumo peruano aún estaba en sus inicios. La persistencia y el incremento moderado de la concentración poblacional en el poblado de Machalilla parece haber estado basado en su cercanía a recursos marítimos. Esta estrategia de subsistencia fue seguramente complementada por un abanico de actividades diversas, las cuales habrían incluido una explotación adicional de recursos terrestres (Harris et al., 2004), así como la producción de bienes suntuarios necesarios para la reproducción cultural local.

\section{Período de Integración (800 - 1532 d.C.)}

Cambios dramáticos son visibles en el paisaje del sur de Manabí durante la parte final de su secuencia cronológica (Figura 8). Quizá el trastorno más significativo en la zona de estudio sea el incremento de la población de Machalilla (diez veces mayor a la cifra registrada para el período anterior), con suficiente evidencia cerámica como para dar cuenta de entre mil setecientas a tres mil quinientas personas viviendo en un área de cerca de cien hectáreas. Este desarrollo ubica sin duda alguna a Machalilla al tope de la jerarquía de asentamiento, como centro regional floreciente. Otro cambio notorio es la presencia de cantidades considerables de habitantes en las bajas elevaciones de las lomas que bordean el llano fluvial meridional del valle de Buenavista, el cual corresponde precisamente a lo que se conoce comúnmente como «Complejo Arqueológico de Agua Blanca», y posiblemente al antiguo poblado de Çalangome (Currie, 1995a, 1995b; McEwan, 2003; Piana y Marotzke, 1997; Silva, 1984). No obstante, contrariamente a Machalilla, la ocupación de Agua Blanca da cuenta de un panorama muy diferente en lo que se refiere a la estructura del asentamiento. Si bien entre novecientas y mil ochocientas personas vivían al pie de estas lomas meridionales (en cualquier momento dado del período de Integración), esta población cubría un área ocupacional mucho más amplia que la franja costanera, es decir, doscientas ochenta hectáreas aproximadamente. La ocupación de Agua Blanca es tan vasta en términos de su distribución espacialcubriendo alrededor de dos a tres kilómetros de este a oeste-que no sería apropiado pensarla como una sola comunidad local. A esta escala de distancias, es poco probable que todos los pobladores de Agua Blanca hayan estado diariamente en interacción directa entre ellos. Sin embargo, la distribución espacial de esta ocupación, la cual se limita a este conjunto particular de planicies bajas al sur del valle de Buenavista, visible en la Figura 8 , representa de alguna manera un tipo de asentamiento distinto y cohesivo, diferente a lo que se presenta en el resto del área de estudio.

Existen también dos otras áreas que dan cuenta de poblaciones lo suficientemente importantes incluidas dentro de localidades lo suficientemente pequeñas como para ser consideradas comunidades locales durante el período de Integración. La primera consiste en una concentración de lotes cerámicos más densos que se presenta justo al norte del valle de Buenavista, mientras que la segunda se ubica precisamente en el poblado actual de San Isidro (Figura 8). En lo que se refiere a la concentración del norte de Buenavista $(\mathrm{NBv})$, existe suficiente material cerámico como para proyectar una cifra de entre ochenta y ciento sesenta individuos viviendo en un área de aproximadamente veinte hectáreas. La ocupación de San Isidro es ligeramente menor, con una población que debió oscilar 
entre los setenta y ciento cuarenta habitantes, en un área de alrededor de quince hectáreas. Fuera de estos asentamientos, aproximadamente sesenta familias (esto es, entre trescientas y seiscientas personas), parecen haber vivido en forma dispersa a lo largo del área de estudio, en unidades domésticas aisladas.

A nivel regional, nuestras proyecciones demográficas estiman la población total del área de estudio en un rango comprendido entre tres mil ciento cincuenta y seis mil trescientas personas. En términos de subsistencia, la distribución de asentamientos de la población regional sí da cuenta de una importancia creciente en la explotación de recursos terrestres a través de un incremento de asentamientos tierra adentro. Desde este punto de vista, la ocupación de Agua Blanca en particular - cerca al valle de Buenavista, irrigado en épocas de lluvia - es principalmente la causa de este cambio, aunque la aparición de nuevas comunidades tierra adentro, al norte de Buena Vista y en San Isidro, constituye también un desarrollo significativo en ese sentido. Sin embargo, vale recalcar que si bien una gran parte de los pobladores locales escogió ubicar sus asentamientos tierra adentro, Machalilla sigue siendo el centro demográfico más obvio, que concentró a más de la mitad de la población regional total. Aunque el número de individuos que habitaron esta comunidad se incrementó radicalmente en comparación con el período anterior, su población no se esparció como en el caso de Agua Blanca.

En Machalilla, cada familia habría poseído menos de la mitad de una hectárea de terreno, superficie lo suficientemente amplia como para incluir huertas domésticas. Adicionalmente, Machalilla se ubica relativamente cerca de áreas bien drenadas en la época de lluvias, lo cual permite llevar a cabo una actividad agrícola moderada durante algunos meses del año. Sin embargo, la mayor parte del año, el área de estudio recibe bajas precipitaciones, y en la actualidad, el alterado y corto curso de la época de lluvias no da lugar a un ambiente propicio para el desarrollo de una actividad agrícola a gran escala. Por esta razón, la subsistencia de la mayoría de los habitantes de Machalilla se basa hoy en día en la pesca (Bauer, 2007). En este sentido, el hecho que la comunidad más poblada dentro del área de estudio se haya ubicado en relación directa con el océano es una prueba contundente de la relevancia de los recursos marítimos en la selección de la ubicación de asentamientos.

Agua Blanca, al contrario, presenta un patrón de asentamiento disperso, en el que cada familia tenía acceso a una hectárea y media de terreno en promedio, superficie mucho más favorable a la práctica de actividades agrícolas organizadas en torno a la tenencia de tierras. Tomando en cuenta que esta ocupación se encuentra justo al pie de las lomas del Valle Buenavista - en donde el rendimiento agrícola es mayor - es probable que cada familia viviera en la parcela de tierra que cultivaba. Esta ubicación fue probablemente ocupada en una escala más densa que otras áreas situadas tierra adentro ya que ofrecía un mejor entorno para el despliegue de estrategias de producción no basadas en recursos marítimos.

Consiguientemente, el panorama aquí esbozado evidencia que, si bien la importancia proporcional de la subsistencia tierra adentro creció de alguna manera, el asentamiento marítimo de Machalilla encabezó el crecimiento poblacional de la región al atraer grandes cantidades de individuos en un patrón de asentamiento denso. Con el incremento de las cifras poblacionales a nivel regional, sería natural esperar que los habitantes de la zona se 
dispersen hacia nuevas localidades en donde podían sacar provecho de otros recursos del área de estudio, más allá de Machalilla. En los dos períodos anteriores, la concentración poblacional relativamente más densa en este asentamiento costanero pudo ser explicada en términos de estrategias de subsistencia basadas en la adquisición de recursos de tipo $r$, la cual estimuló la concentración moderada de asentamientos. No obstante, esta explicación parece insuficiente a la hora de justificar el incremento poblacional radical de la comunidad de Machalilla identificado para el período de Integración. Los recursos $r$ habían existido ya por más de cuatro mil años, durante los cuales la población de Machalilla se había mantenido en un nivel relativamente bajo y estable.

En términos de complejidad sociopolítica, las fuentes etnohistóricas de la época de la conquista española atestiguan un grado marcado de estratificación social al sur de Manabí. Tal como fue subrayado más arriba, la estructura política de la región es descrita como una entidad política cohesiva - llamada Çalangome - y unificada bajo la égida de un solo dirigente que controlaba cuatro asentamientos (Currie, 1995a, 1995b; Pizarro, 1844a [1527], 1844b [1571]). Esto sugiere que el área de nuestra zona de estudio (que incluye dos de los cuatro asentamientos previamente mencionados) corresponde a una fracción de una unidad política más amplia, al menos para la época de la conquista europea. Los datos arqueológicos del período de Integración recuperados en el área de estudio parecerían corroborar este escenario.

En primer lugar, el drástico aumento demográfico en los asentamientos de Machalilla y Agua Blanca constituye el primer indicador de la aparición de cambios sociales en el período de Integración. En lo que se refiere a la comunidad de Machalilla, caben pocas dudas que la presencia de algunos miles de habitantes dentro de un área de aproximadamente cien hectáreas produjera al menos cierto grado de fricción social, el cual requeriría la presencia de mecanismos orientados a proveer una mejor articulación social. En el caso de Agua Blanca, la dispersión relativa del patrón poblacional podría haber disminuido la interacción social y requerido una integración política menor. Sin embargo, la cantidad sustancial de vestigios de complejos arquitectónicos da cuenta de la presencia de algún tipo de instituciones políticas organizadas dentro de este asentamiento. El complejo arqueológico de Agua Blanca es quizá más conocido por sus estructuras de superficie denominadas «corrales», las cuales pertenecen al período de Integración, y consisten en largos muros de fundación de piedra (similares a los «corrales» usados en la ganadería), sobre los cuales muros de caña, bahareque y enlucido sostenían techos de paja. Muchos de ellos fueron identificados como estructuras domésticas, aunque en algunos casos, se ha hablado también de casas comunales o de élites (McEwan, 2003). Las más notorias entre estas estructuras se ubican en lo que actualmente se conoce como el «centro ceremonial», un área de aproximadamente cuarenta hectáreas, ubicada al sur del poblado actual de Agua Blanca. Esta área no sólo cuenta con más de veintiocho estructuras con base de piedra, sino también casas que constituyen los «corrales» más complejos de todo el Parque Nacional. Una de ellas es una estructura de 50 x 15 metros aproximadamente, que contiene vestigios de nueve «sillas manteñas» (o «sillas de poder») de piedra tallada. Puesto que las sillas de este tipo se ubican en todo el valle, McEwan (2003) ha sugerido que eran usadas por las élites de distintos grupos corporativos, como parte de sus ceremonias rituales al sol. Este tipo de estructuras muy elaboradas, así como sus sillas metódicamente grabadas, no han sido registradas en períodos más tempranos, 
lo cual indica al menos cierto grado de cambio en las instituciones políticas aceptadas (o padecidas) por la población general.

La distribución del patrón de asentamiento a nivel regional evidencia además una organización espacial que rebasa la simple escala de comunidades locales. La Figura 9 ilustra un rendimiento de perspectiva progresivamente suavizado de la cerámica del período de Integración. Éste demuestra que, a medida que el suavizado incrementa, los vestigios de la ocupación de Agua Blanca permanecen separados de los de Machalilla, bajo la forma de un distrito de interacción independiente. Este distrito abarca además a los asentamientos cercanos, los cuales incluyen la totalidad de la población del valle de Buenavista. Hasta la perspectiva más suavizada $(0,25)$ produce dos distritos de interacción distintos, cada cual con su propio punto central. Esta distribución del área en distritos cohesivos sugiere que otras fuerzas podrían haber afectado — o más directamente, organizado - al patrón de asentamiento y, paralelamente, a los intereses más localizados de las comunidades individuales.

Si examinamos los componentes de artefactos en las diversas comunidades, percibimos también evidencias notorias de diferenciación de estatus entre ellas. Siguiendo el mismo principio aplicado para el Desarrollo Regional, la Figura 10 emplea dos criterios de medición de la proporción de cerámica fina para diversos asentamientos del área de estudio. Ya que la ocupación de Agua Blanca es demasiado dispersa como para ser descrita como una sola comunidad local propiamente dicha, la línea de contorno que encierra esta ocupación es representada por una línea cortada. La Figura 10a ilustra la proporción de fragmentos de cerámica fina sobre el total de material cerámico recuperado en las diversas ocupaciones; la Figura 10b representa la proporción de fragmentos cerámicos altamente pulidos sobre la cantidad total de cerámica recogida. Con excepción de algunas leves diferencias, el panorama general observado aquí evidencia el mismo patrón básico. Tal como se lo pudiera haber esperado, la ocupación rural dispersa tiene las proporciones más bajas de indicadores de estatus. Entre los dos grandes asentamientos, ambos criterios le otorgan a Machalilla mayores índices indicadores de estatus que a Agua Blanca. La pequeña comunidad de San Isidro da cuenta de indicadores de estatus en el rango de Machalilla y Agua Blanca. Al contrario, la pequeña comunidad del Norte de Buenavista presenta de muy lejos los mayores indicadores de cerámica elaborada-especialmente cerámica fina - , lo cual indica que este asentamiento podría haber sido una sede particular de actividades de élites. Aunque el tamaño de las muestras no sea exageradamente grande, los márgenes de error confirman que podemos tener por lo menos un nivel de confianza moderado en que estas diferencias no son el resultado del simple carácter aleatorio del muestreo. Existe un nivel de confianza aún mayor de que la comunidad del Norte de Buenavista tenga efectivamente mayores proporciones de cerámica fina o altamente pulida en comparación a otras ocupaciones de la zona de estudio.

Un énfasis similar es asimismo evidenciado en los componentes de cerámica doméstica sencilla recolectados entre estas comunidades. La Figura 11a, ilustra una comparación de proporciones entre fragmentos cerámicos pertenecientes a platos para preparar yuca o alimentos a base de maíz. Tal como se puede observar, las dos ocupaciones más dispersas (Agua Blanca y las unidades domésticas campesinas aisladas) dan cuenta de un mayor énfasis en cerámica asociada con la preparación de productos agrícolas. Ya que estos platos sólo constituyen una pequeña parte de los componentes domésticos totales, y que 
los fragmentos cerámicos que pudieron ser reconocidos como tales son aún menores, este fenómeno atenuó las diferencias de proporciones. No obstante, los márgenes de error sugieren que existe al menos un nivel de confianza moderado sobre la equivalencia de estas diferencias estadísticas con diferencias reales entre la población. El mismo patrón es visible en la comparación de la cantidad total de tiestos asociados a ollas utilitarias manteñas (probablemente utilizadas para el transporte o almacenamiento de granos u otros tipos de recursos agrícolas) en comparación con la totalidad de fragmentos cerámicos recuperados (Figura 11B). Una vez más, las ocupaciones más dispersas (Agua Blanca y las unidades domésticas aisladas) evidencian mayores proporciones de este tipo de fragmentos en comparación con las dos comunidades concentradas, las cuales presentan un grado mayor de actividad productiva. Es interesante notar aquí que la comunidad de Norte de Buenavista presenta las proporciones más bajas de ollas y platos utilitarios que cualquier otro asentamiento. Esto no sólo sugiere una escasez generalizada de actividades domésticas en este lugar, sino que también fortalece la idea de esta comunidad como un foco particular de actividades de élite.

Así, el período de Integración no sólo significa la aparición de comunidades mucho más numerosas y concentradas a nivel demográfico, sino también el surgimiento de un patrón de asentamiento que da cuenta de un territorio organizado alrededor de distritos supra-locales de interacción. Este período presencia además el desarrollo de los complejos arquitectónicos de «corrales», así como la aparición de las famosas sillas Manteñas, comúnmente citadas como indicadores de actividades llevadas a cabo por facciones de élites (McEwan, 2003; Piana y Marotzke, 1997). Los componentes cerámicos de las diferentes comunidades evocan el complejo panorama de una organización supralocal y habitacional generalmente asociada a formaciones políticas delimitadas en áreas que rebasan el poblado local o caserío (Carneiro, 1981). Este supuesto corrobora la caracterización etnohistórica del área de estudio, la cual menciona la presencia de un dirigente político ejerciendo control supra-local sobre los asentamientos de la región.

Los recursos marítimos existieron por más de cuatro mil años, a lo largo de los cuales fueron explotados por una concentración mínima de pobladores en la bahía de Machalilla. En este sentido, la drástica expansión demográfica identificada en este punto para el período de Integración se presenta de forma repentina, y sería difícil explicarla a través de los mismos factores que estimularon un poblado pequeño a formarse en esta ubicación durante épocas más tempranas. Tal como se ha observado más arriba, lo que diferencia a este período de las secuencias cronológicas anteriores es la aparición de un mercado considerablemente amplio de consumo de objetos de concha Spondylus en la costa norte de Perú, así como cantidades arqueológicas considerables de este producto en el área estudio y a lo largo de todo el sur de Manabí para la misma época.

Contrariamente a la escasa cantidad de sitios excavados en que se evidenció algún tipo de elaboración de concha durante el período de Desarrollo Regional, una gran cantidad de excavaciones localizadas ha puesto de relieve la evidencia de una producción de cuentas de concha para el Periodo de Integración, tanto en el área de estudio como a lo largo de toda la costa central del Ecuador (Carter, 2008; Currie, 1995a, 1995b; Harris et al., 2004; Martín, 2009b). Fuera del área de estudio, en el sur de Manabí, los sitios de Río Chico, López Viejo y Salango evidencian la producción de objetos de concha Spondylus en el período de Integración; a lo cual se agregan los sitios de Mar Bravo y Loma de 
los Cangrejitos, más al sur (Carter, 2008). Dentro del área aquí prospectada, Mester (1990), ha rescatado zonas de elaboración de concha en el sitio de Los Frailes (Figura 1), fechadas en la transición del período de Integración. La ubicación de estos sitios es representada en la Figura 2. Carter (2008) ha observado que el periodo comprendido precisamente entre 700 y 1300 d.C. presenció un incremento marcado en la producción estandarizada de cuentas de concha. La evidencia malacológica recuperada en el área de prospección parecería corroborar este escenario. Más del 93\% de material cerámico hallado dentro de las concentraciones de concha que contenían fragmentos de Spondylus trabajada pertenece al período de Integración. Esta asombrosa predominancia de material de este período dentro de concheros asociados a la manufactura de concha no sólo indica que la mayoría de actividades relacionadas a la elaboración de este material se dio en la última etapa que antecedió la llegada de los europeos, sino que es además un indicador de la relación existente entre esta industria y los cambios sociales y políticos registrados al sur de Manabí en este momento en particular.

\section{Discusión}

En el área de estudio, la evidencia de actividades de elaboración de objetos de concha está sobre todo presente en la comunidad más poblada (Machalilla), en donde las estimaciones demográficas sugieren que al menos la mitad de la población de esta comunidad explotaba este recurso (Martín, 2009a: 114-151). Otros asentamientos tales como Agua Blanca, el Norte de Buenavista o las unidades domésticas campesinas aisladas dan cuenta de una evidencia marginal de actividades de elaboración de objetos de concha, con menos del $20 \%$ de la población fuera de Machalilla ejerciendo algún tipo de actividades ligadas a ella. Datos extraídos de prospecciones indican también que esta industria se expandió con fuerza durante el período de Integración, al florecer los mercados peruanos de Spondylus y otras conchas exóticas (Carter, 2008; Martín, 2007; Shimada, 1994). Es también durante este período que, por primera vez en la trayectoria local de desarrollo, las cifras demográficas se incrementan considerablemente. Este crecimiento regional de la población parece estar primeramente encabezado por Machalilla, asentamiento que se expande mucho más que cualquier otro a nivel demográfico, alcanzando más de la mitad de la población regional, y sigue presentando un patrón poblacional más denso y concentrado que el resto de la región. La mayoría de evidencia de actividades de elaboración de objetos de concha Spondylus en superficie también se da en este lugar (Martín, 2009a). Sería razonable asumir que esta industria estaba de alguna manera ligada a los factores que permitieron a Machalilla mantener niveles poblaciones mayores en esa época. Tal como es de esperarse, paralelamente a la expansión demográfica de Machalilla, las cifras de la población regional también se incrementan. Una cantidad mayor de individuos se aprovechan de las planicies anegadizas del valle de Buenavista, así como de las pequeñas comunidades del Norte de Buenavista y de San Isidro. No obstante, se recalcará que estas áreas, en las que se enfatizó la explotación de recursos terrestres, evidenciaron un patrón de asentamiento más disperso que el de Machalilla, mucho más densamente ocupado. Por naturaleza, a más de representar un beneficio adicional para la 
unidad doméstica, las actividades de elaboración de conchas no requieren la ocupación de grandes superficies de terreno, por lo cual pudieron efectivamente haber constituido la base de un incremento y una mayor concentración demográficos.

Si bien la ocupación de Agua Blanca es tradicionalmente considerada en la larga historia académica de la costa del Ecuador como un centro de élite regional (debido principalmente a la presencia de su complejo arquitectónico de corrales), cabe acotar que la mayoría de evidencia de cerámica fina se presenta en Machalilla, y más aún en el extremadamente pequeño asentamiento del Norte de Buenavista. Adicionalmente, Norte de Buenavista es la comunidad en donde los equipos de prospección recuperaron la evidencia más escasa de trabajo de concha en general (Martín, 2009a). Sin embargo, presenta los indicadores más abrumadores de estatus - incluyendo altas proporciones de cerámica fina y bajas cantidades de vajilla doméstica/utilitaria — así como de platos para la preparación doméstica de productos agrícolas. Esta discrepancia entre el asentamiento con los mayores indicadores de élite y la más baja evidencia de la elaboración de objetos de concha es lo contrario de lo que se esperaría si las élites controlaran la producción por medio de artesanos adjuntos (Smith, 2004). Al contrario, las prospecciones evidenciaron una mayor producción de objetos de concha en Machalilla, el poblado más denso y más poblado, en donde más del cincuenta por ciento de la población parece haber llevado a cabo estas actividades (Martín, 2009a: 114-151).

En realidad, la influencia de esta actividad en el desarrollo sociopolítico parece estar más ligada a los principios económicos que presionaron a las unidades familiares individuales a vivir en patrones de asentamientos más grandes y compactos que en épocas anteriores. Las unidades domésticas parecen haber sacado provecho del surgimiento de mercados de consumidores en el actual territorio peruano al incluir esta industria productiva en su repertorio de subsistencia, paralelamente a otras estrategias. Autores como Masucci (1995) han notado que la producción de artículos no-perecederos tales como éstos sirve generalmente como una forma de ingreso suplementaria - más estable - que ayuda a las unidades familiares a paliar las incertidumbres climáticas así como los años de baja productividad agrícola. La necesidad de estas unidades familiares de reubicarse en las cercanías de los puntos de explotación de estos recursos explicaría seguramente el rápido crecimiento demográfico observado en Machalilla durante este período.

El incremento demográfico subsiguiente y la mayor concentración del patrón de asentamiento evidenciados en este punto están temporal y espacialmente asociados a un patrón de asentamiento regional más complejo que incluye formas supra-locales de organización, así como una mayor diferenciación de estatus entre asentamientos. En este sentido, el incremento de la concentración poblacional y la aceleración del crecimiento demográfico evidenciados en Machalilla en este punto hubieran probablemente requerido un incremento en las formaciones sociopolíticas que permiten una mejor articulación y fluidez social, estimulando a la vez los más altos niveles de complejidad política y social evidenciados en esta época.

Este estado de hechos sugiere que el sur de Manabí tuvo efectivamente una trayectoria de desarrollo particular, en la cual el intercambio de objetos exóticos elaborados de concha 
jugó un papel importante en el desarrollo sociopolítico, pero solo después del comienzo del consumo masivo de estos objetos por parte de las poblaciones peruanas (en particular por parte de los estados Sicán y Chimú) durante el período entre 700 - 1300 d.C. (Carter, 2008). En nuestra zona de estudio no existe evidencia que esta industria influyó en el patrón de complejidad regional durante períodos anteriores. Así mismo es poco probable que durante el Período de Integración el papel de la producción de objetos de concha haya sido tan pronunciado como para que las poblaciones del sur de Manabí hayan dependido de su intercambio o de relaciones simbióticas con sus vecinos a fin de asegurar su subsistencia. Hay que resaltar que la composición del patrón de asentamiento del período de Integración sugiere más que nada que esta industria complementó un abanico más amplio de actividades de subsistencia-las cuales probablemente incluían, entre otras, la pesca y algunas tareas agrícolas — y que fuera de la comunidad de Machalilla, la mayoría de la población regional no sacó provecho de las actividades de elaboración de objetos de concha.

A modo de balance, subrayaremos que la investigación presentada aquí ilustra la necesidad de afinar el concepto de complejidad tal como se lo maneja en la arqueología regional, así como de revisar las diversas propuestas existentes en torno a los procesos de complejización social en la costa ecuatoriana en particular. Desde este punto de vista, vale recordar que la arqueología maneja un gran número de modelos que requieren no obstante ser constantemente redefinidos y pulidos en base a evidencias empíricas específicas. El presente caso es un ejemplo más de este proceso de enriquecimiento constante.

En la literatura académica, nos hemos acostumbrado en las últimas décadas ha generar modelos de complejidad social basados en el control élite de unos pocos artesanos especializados que trabajan a tiempo completo para el beneficio ideológico o económico de sus líderes políticos (Kipp y Schortman, 1989). La evidencia presentada aquí sugiere un escenario distinto en el cual la producción de objetos suntuarios parece haberse organizado en torno a las unidades domesticas como complemento a un abanico más amplio de estrategias de subsistencia, y que no demuestran ninguna asociación particular con las élites regionales. La presión de esta industria en el desarrollo sociopolítico, entonces, parece estar más basada en que la disponibilidad de este recurso durante el período de Integración causó crecimientos demográficos al atraer a mayores cantidades de unidades domésticas a espacios concentrados donde podían explotar esta producción complementaria. Dicha concentración poblacional, inevitablemente, hubiese requerido el desarrollo de mayores estructuras políticas administrativas que pudiesen brindar una mejor articulación social a estas grandes cantidades de familias conviviendo en espacios concentrados.

Es también muy probable que estos factores no hayan sido igual de importantes en el desarrollo de la complejidad social en otras áreas de la costa ecuatoriana. Tomando en cuenta el hecho que en la actual provincia de Guayas - contrariamente al área de Manabí - el potencial agrícola es mucho mayor (tal como lo revela Delgado, 2006), es altamente probable que la trayectoria de desarrollo en ese sector haya sido diferente, quizá semejante a lo propuesto por Stemper (1993) para Milagro-Quevedo. Es decir, 
una complejidad social basada en el financiamiento de necesidades básicas agrícolas. Más al norte, en La Tolita, Valdez (2007) señala más bien que la ideología pudo haber tenido un papel crítico en la definición de la complejidad política de esa zona. Esto reitera que el conglomerar a todas las sociedades costeras ecuatorianas bajo el nombre de la «Liga de Mercaderes Manteños» es una tradición académica que quizás tenga más efectos negativos que favorables en nuestro análisis de éstas, ya que nubla los posibles - e importantes - factores sociales detrás del desarrollo jerárquico de cada población. Esta posible variedad reitera la importancia en el intercambio de ideas entre los investigadores de la costa ecuatoriana, y la necesidad de adquirir un "reflejo comparativo" para un mejor entendimiento de nuestro pasado.

\section{Agradecimientos}

Robert Drennan contribuyó múltiples y valiosos comentarios que orientaron la formulación de estas ideas. Esta investigación fue posible gracias a la beca de la National Science Foundation (número de adquisición: 0638456) y al Howar Heinz Endowment Graduate Fellowship.

\section{Figuras}

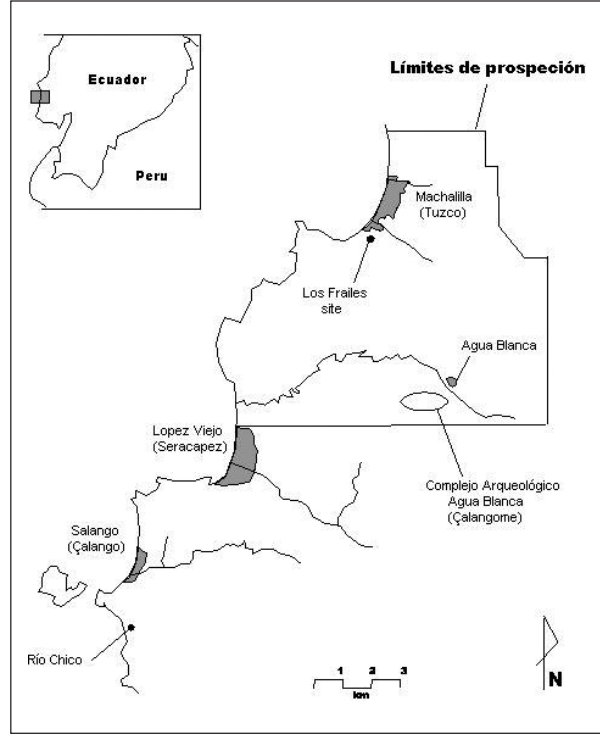

Figura 1.

Asentamientos modernos, ubicación supuesta de los pueblos de Çalangome, y límites del área prospectada.

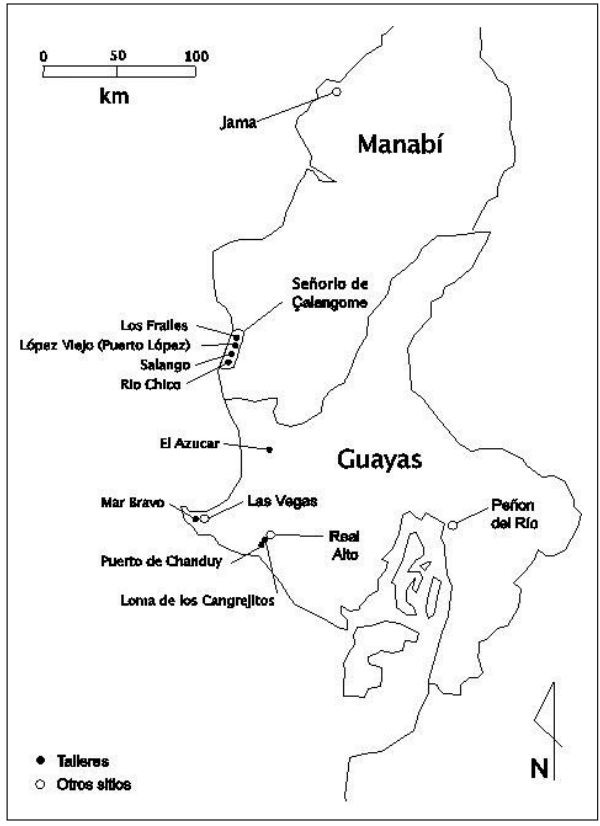

Figura 2.

Talleres de elaboración de concha y sitios del litoral ecuatoriano. 


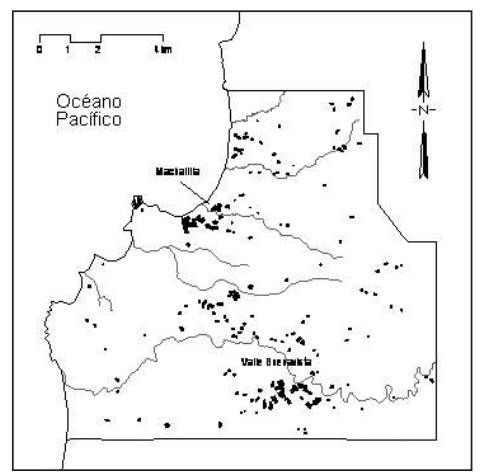

\section{Figura 3.}

Lotes dentro del área de estudio en que se recuperó cerámica del período Formativo (mitad izquierda) y perspectiva de rendimiento de densidad cerámica (mitad derecha). Los picos representan áreas de alta concentración de material cerámico, mientras que las áreas planas ilustran los espacios del área prospectada en que no se recuperó ningún material cerámico.
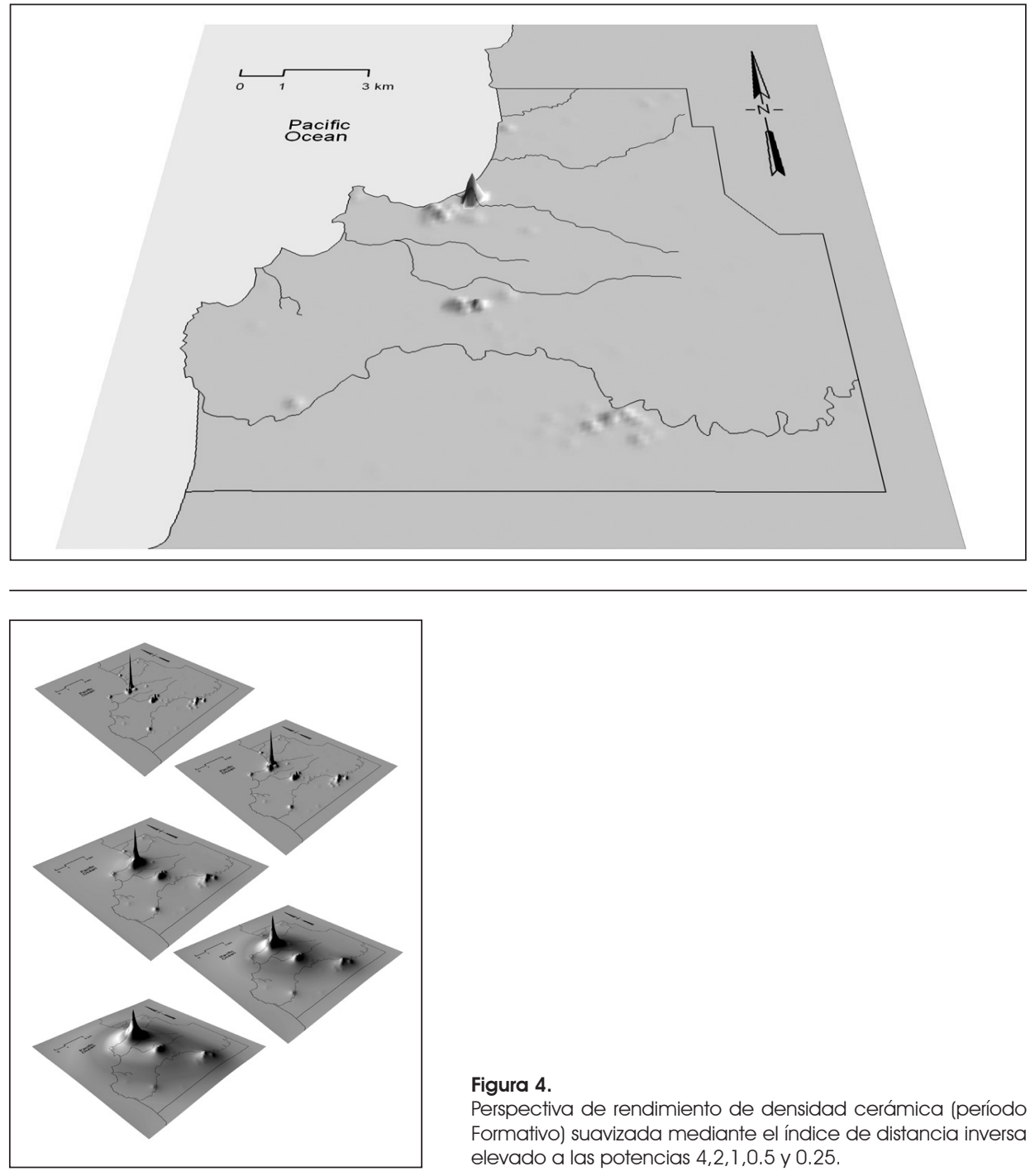

Figura 4.

Perspectiva de rendimiento de densidad cerámica (período Formativo) suavizada mediante el índice de distancia inversa elevado a las potencias $4,2,1,0.5$ y 0.25 


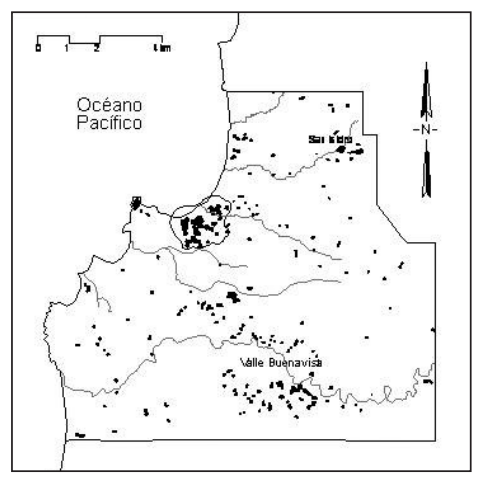

\section{Figura 5.}

Lotes dentro del área de estudio en donde se recuperó material cerámico del período de Desarrollo Regional (mitad superior) y puesta en perspectiva del rendimiento de densidad cerámica (mitad inferior). Los picos representan las áreas de alta concentración de material cerámico, y los espacios planos ilustran las zonas del área prospectada en que no se recuperó ningún material cerámico. Las delimitaciones de la comunidad de Machalilla están también representadas.
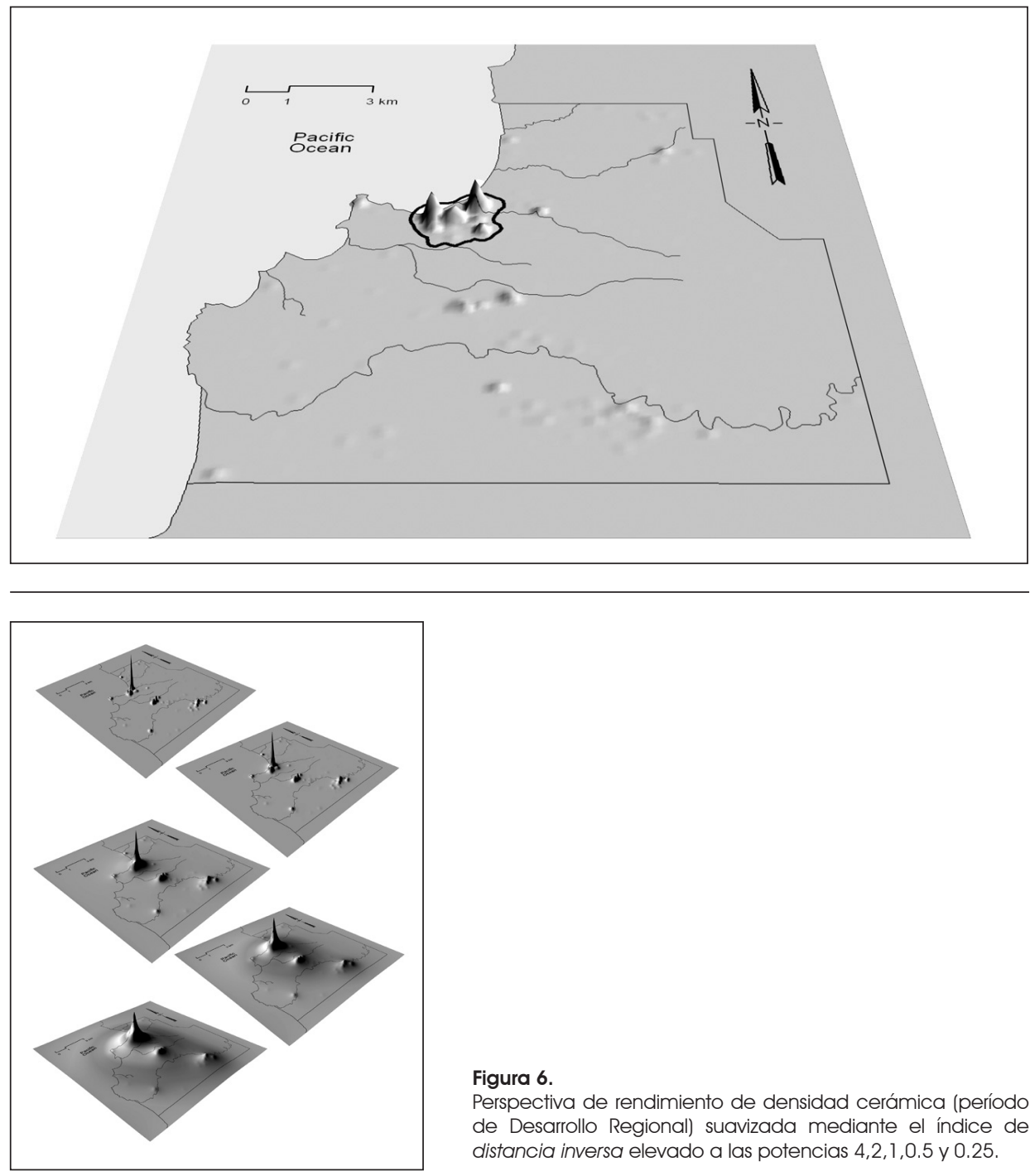

Figura 6.

Perspectiva de rendimiento de densidad cerámica (período de Desarrollo Regional) suavizada mediante el índice de distancia inversa elevado a las potencias $4,2,1,0.5$ y 0.25 . 


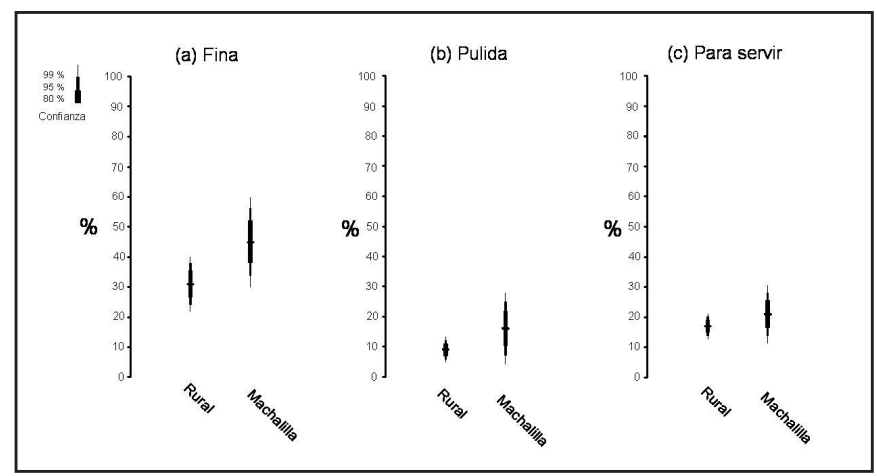

\section{Figura 7.}

Proporciones de material cerámico (período de Desarrollo Regional): a) proporción de fragmentos de «cerámica fina» sobre el total de fragmentos cerámicos recuperados; b) proporción de fragmentos cerámicos altamente pulidos sobre el total de fragmentos cerámicos recuperados; c) proporción de fragmentos correspondientes a «vajilla para servir» sobre el total de material cerámico recuperado.

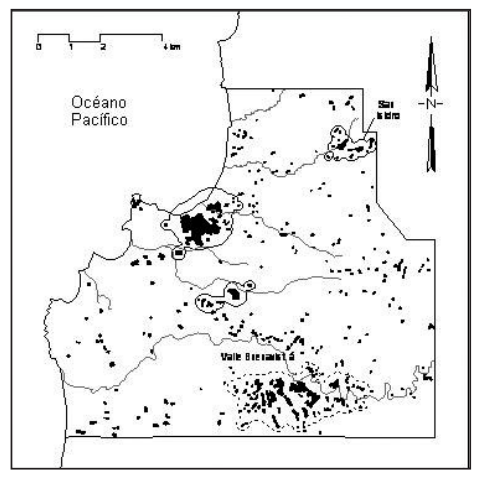

\section{Figura 8.}

Lotes dentro del área de estudio en donde se recuperó material cerámico del período de Integración (mitad superior) y perspectiva de rendimiento de densidad cerámica (mitad inferior). Los picos representan las áreas de alta concentración de material cerámico, y los espacios planos ilustran las zonas del área prospectada en que no se recuperó ningún material cerámico. Las delimitaciones de los diversos asentamientos del período de Integración están también representadas.

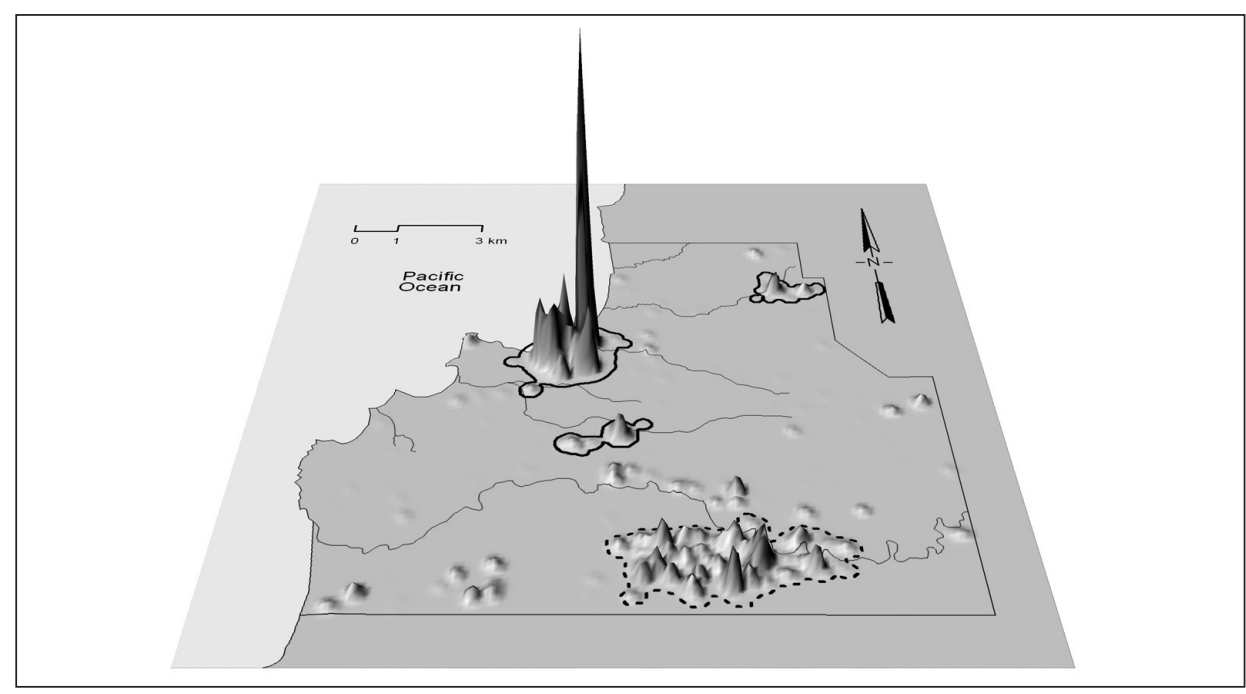




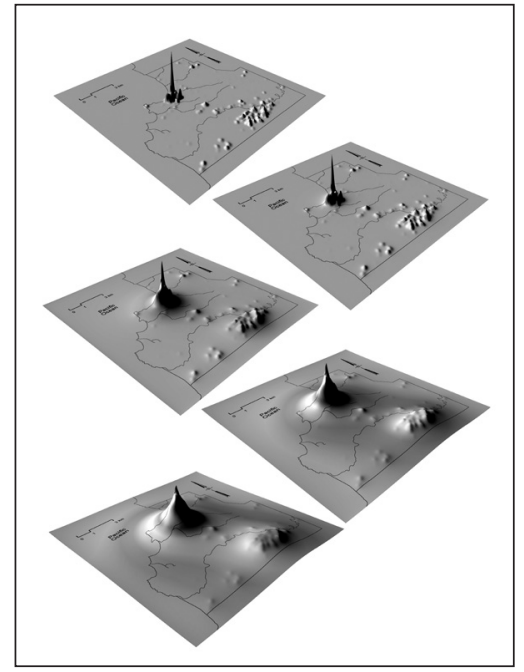

Figura 9.

Puesta en perspectiva de rendimiento de densidad cerámica (período de Integración) suavizada mediante el índice de distancia inversa elevado a las potencias $4,2,1,0.5$ y 0.25 .

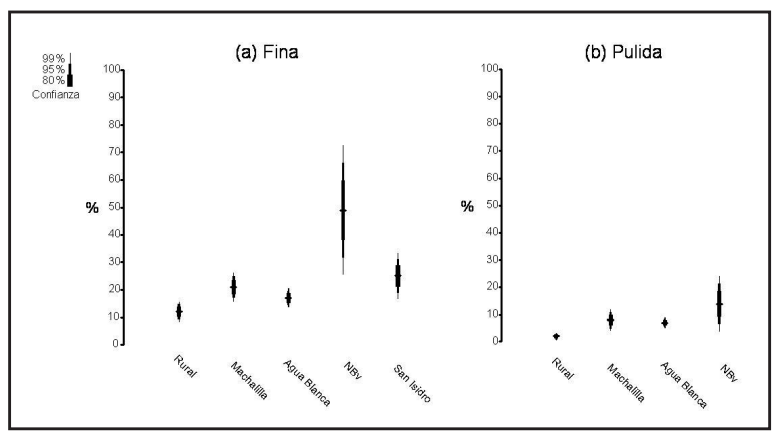

Figura 10. Proporciones de material cerámico (período de Integración): a) proporción de fragmentos de "cerámica fina" sobre el total de fragmentos cerámicos recuperados; b) proporción de fragmentos cerámicos altamente pulidos sobre el total de fragmentos cerámicos recuperados.

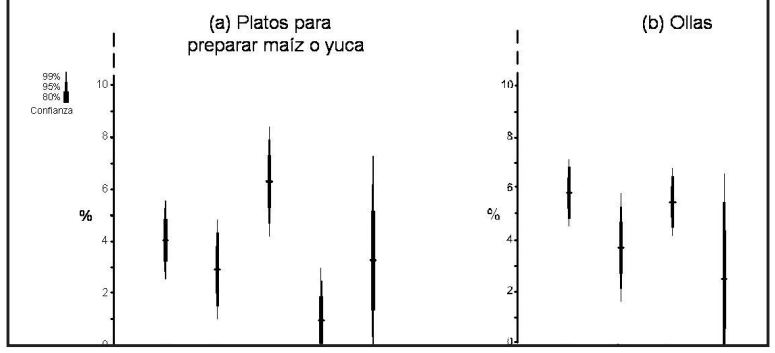

Figura 11.

Proporción de fragmentos cerámicos del período de Integración:

a) proporción de fragmentos cerámicos pertenecientes a platos para preparar yuca o alimentos a base de maíz la menudo indebidamente designados como «ralladores manteños») sobre el total de material cerámico recuperado; b) proporción de fragmentos cerámicos pertenecientes a ollas grandes utilitarias sobre el total de fragmentos cerámicos recuperados. 


\section{Bibliografía}

Abbott, R. Tucker, 1974, American Seashells, Van Nostrand Reinhold Co., New York.

Akazawa, Takeru, 1986, "Hunter-gatherer Adaptations and the Transitions to Food Production in Japan", en: M. Zvelebil, (ed.), Hunters in Transition: Mesolithic Societies of Temperate Eurasia and their Transition to Farming, Cambridge, University Press, Cambridge, pp. 151-166.

Bauer, Daniel, 2007, "The Reinvention of Tradition: An Ethnographic Study of Spondylus Use in Coastal Ecuador", Journal of Anthropological Research 63, University of New Mexico, Albuquerque, pp. 33-49.

Boada Rivas, Ana María, 2007, The Evolution of Social Hierarchy in a Muisca Chiefdom of the Northern Andes of Colombia. University of Pittsburgh Memoirs in Latin American Archaeology 17, University of Pittsburgh Latin American Archaeology Publications, Pittsburgh.

Blanton, Richard, et al., 1996, "A Dual-Processual Theory for the Evolution of Mesoamerican Civilization", Current Anthropology 37(1), The University of Chicago Press, Chicago, pp. 1-14.

Blanton, Richard, et al., 1982, Monte Albán's Hinterland, Part I: The Prehispanic Settlement Patterns of the Central and Southern Parts of the Valley of Oaxaca, Mexico. Memoirs of the Museum of Anthropology, University of Michigan 15, University of Michigan, Ann Arbor.

Carneiro, Robert, 1981, "The Chiefdom: Precursor to the State", en: G. Jones y R. Kautz, (eds.), The Transition to Statehood in the New World, Cambridge University Press, Cambridge, pp. 37-79.

Carter, Benjamin Philip, 2008, Technology, Society and Change: Shell Artifact Production Among the Manteño (A.D. 800-1532) of Coastal Ecuador. Tesis Doctoral, Washington University, St. Louis, ProQuest/UMI.

Cordy-Collins, Alana, 1990, “Fonga Sigde, Shell Purveyor to the Chimú Kings”, en: M.E. Moseley and A. Cordy-Collins, (eds.), The Northern Dynasties: Kingship and Statecraft in Chimor, Dumbarton Oaks Research Library and Collection, Washington D.C., pp. 393-417.

Cuellar, Andrea M., 2006, The Organization of Agricultural Production in the Emergence of Chiefdoms in the Quijos Region, Eastern Andes of Ecuador. Tesis Doctoral, University of Pittsburgh, ProQuest/UMI, Pittsburgh.

Currie, Elizabeth J., 1995a, "Archaeology, Ethnohistory and Exchange Along the Coast of Ecuador", Antiquity 69 (264), Society of American Archaeology, pp.511-526.

1995b, Prehistory of the Southern Manabi Coast, Ecuador: López Viejo. BAR International Series 618, Tempus Reparatvm, Oxford.

Delgado Epinoza, Florencio, 2002, Intensive Agriculture and Political Economy of the Yaguachi Chiefdom of Guayas Basin, Tesis Doctoral, University of Pittsburgh, ProQuest/UMI, Pittsburgh.

2006, "Organización de la Producción de los Camellones de la baja Cuenca del Guayas durante la ocupación de los Chonos", en: Valdez, Francisco (ed)., Agricultura Ancestral Camellones y Albarradas, Abya-Yala, Quito, pp. 159-168.

Drennan, Robert, 2006, Prehispanic Chiefdoms in the Valle de la Plata, Volume 5: Regional Settlement Patterns. University of Pittsburgh Memoirs in Latin American Archaeology 16, University of Pittsburgh Latin American Archaeology Publications, Pittsburgh.

1996, Statistics for Archaeologists: A Common Sense Approach, Plenum Press, New York.

1988, "Household Location and Compact versus Dispersed Settlement", en: Wilk, R. and W. Ashmore, (eds.), Household and Community in the Mesoamerican Past, University of New Mexico, Albuquerque, pp. 273-293.

Drennan, Robert D. et al., 2003a, “Approaches to Regional Demographic Reconstruction”, en: Regional Archaeology in Eastern Inner Mongolia: A Methodological Exploration, Science Press, Beijing, pp. 152-165.

Drennan, Robert D., et al., 2003b, Chapter 3: Methods for Archaeological Settlement Study, en Regional Archaeology in Eastern Inner Mongolia: A Methodological Exploration, Science Press, Beijing, pp. 122-151.

Earle, Timothy K., 1997, How Chiefs Come to Power: The Political Economy in Prehistory, Stanford University Press, Stanford. 
Fish, Suzanne, y Stephen Kowalewski, (eds.), 1990,The Archaeology of Regions, Smithsonian Institution Press, Washington D.C.

Fried, M., 1967,The Evolution of Political Society, Random House, New York.

Haller, Mikael John, 2008, Asiento Viejo and the Development of the Rio Parita Chiefdom,Panama. University of Pittsburgh Memoirs in Latin American Archaeology 19, University of Pittsburgh Latin American Archaeology Publications, Pittsburgh.

Harris, Michael, et al., 2004, "The Complex Interplay of Culture and Nature in Coastal South-Central Ecuador: An Interdisciplinary Work", Expedition 46 (1), 38-43.

Kim, Bumcheol, 2005, Rice Agricultural Intensification and Sociopolitical Development in the Bronze Age, Central Western Korean Peninsula. Tesis Doctoral, University of Pittsburgh, ProQuest/ UMI, Pittsburgh.

Kipp, Rita Smith y Edward M. Schortman, 1989, "The Political Impact of Trade in Chiefdoms", American Anthropologist, American Anthropological Association, Blackwell Publishing, 91(2), pp. 370-385.

Keen, Myra, 1971, Sea Shells of Tropical West America, Stanford University Press, Stanford.

Kowalewski, Stephen A. et al., 1989, Monte Albán's Hinterland, Part II: Prehispanic Settlement Patterns in Tlacolula, Etla, and Ocotlán, the Valley of Oaxaca, Mexico. Memoirs of the Museum of Anthropology, University of Michigan 23, Ann Arbor, University of Michigan.

Langebaek, Carl Henrik, 1995, Regional Archaeology in the Muisca Territory: A Study of the Fúquene and Susa Valleys. University of Pittsburgh Memoirs in Latin American Archaeology 9, University of Pittsburgh Latin American Archaeology Publications, Pittsburgh.

Lunniss, Richard, 2007, "Una Casa Ceremonial del Formativo Tardío en Salango, Manabí”, en: F. García, (ed.), II Congreso Ecuatoriano de Antropología y Arqueología, Volumen 1, Abya-Yala, 409-432, Quito.

2001, Archaeology at Salango, Ecuador: an Engoroy Ceremonial Site on the South Coast of Manabi. Tesis Doctoral, University College London, ProQuest/UMI, London.

Marcos, Jorge G., 1995, "El Mullo y el Pututo: La Articulación de la Ideología y el Tráfico a Larga Distancia en la Formación del Estado Huancavilca", en: Álvarez, S.G. et al., Primer Encuentro de Investigadores de la Costa Ecuatoriana en Europa, Abya-Yala, Quito, pp. 97-142.

1977/78, "Cruising to Acapulco and Back with the Thorny Oyster Set", Journal of the Steward Anthropological Society 9 (1-2), 99-133.

Martín, Alexander J., 2009a, The Domestic Mode of Production and the Development of Sociopolitical Complexity: Evidence from the Spondylus Industry of Costal Ecuador. Tesis Doctoral, University of Pittsburgh, ProQuest/UMI, Pittsburgh.

2009b, "Comparing the Role of the Export Sector in Prehistoric Economies: The Importance of Shell Manufacture to the Livelihood of Coastal Ecuadorian Populations", en: Cutright, R.E. et al., (eds.), Comparative Perspectives on the Archaeology of Coastal South America, University of Pittsburgh Center for Comparative Archaeology, Pittsburgh.

2007, "El Intercambio de Spondylus a lo Largo de la Costa Sudamericana de Acuerdo al Registro Arqueológico", en: García, Fernando (ed.), II Congreso Ecuatoriano de Antropología y Arqueología. Balance de la Última Década: Aportes, Retos y Nuevos Temas, Volumen 1, AbyaYala, Quito, pp. 433-462.

Masucci, Maria Ann, 1995, "Marine Shell Bead Production and the Role of Domestic Craft Activities in the Economy of the Guangala Phase Southwest Ecuador", Latin American Antiquity 6 (1), Society of American Archaeology, 70-84.

McEwan, Colin, 2003, 'And the Sun Sits in his Seat': Creating Order in Andean Culture. Tesis Doctoral, University of Illinois Urbana-Champaign, Urbana-Champaign, ProQuest/UMI.

Mester, Ann Marie, 1990, The Pearl Divers of Los Frailes: Archaeological and Ethnohistorical Explorations of Sumptuary Good Trade and Cosmology in the North and Central Andes. Tesis Doctoral, University of Illinois Urbana-Champaign, Urbana-Champaign, ProQuest/UMI.

Moseley, Michael E., 1992, "Maritime Foundations and Multilinear Evolution: Retrospect and Prospect", Andean Past 3, 5-42.

1975, The Maritime Foundations of Andean Civilization, Menlo Park, Cummings. 
Murra, John V., 1982, "El Tráfico de Mullu en la Costa del Pacífico", en: J. Marcos y P. Norton, (eds.), Primer Simposio de Correlaciones Antropológicas Andino-Mesoamericano, July 25-31, 1971, Escuela Superior Politécnica del Litoral, Guayaquil, pp. 265-274.

Murillo Herrera, Mauricio, 2009, Social Change in Pre-Columbian San Ramón de Alajuela, Costa Rica, and its Relation with Adjacent Regions. Tesis Doctoral, University of Pittsburgh, ProQuest/UMI, Pittsburg.

Muse, Michael, 1989, "Corrología Regional y Relaciones de Territorialidad en la Región Oeste del Area Septentrional Andina, Siglo XVI", en: J.-F. Bouchard y M. Guinea, (eds.), Relaciones Interculturales en el Area Ecuatorial del Pacifico Durante la Epoca Precolombina. BAR International Series 503, Tempus Reparatvm, Oxford, pp. 187-197.

Norton, Presley, 1986, "El Señorío de Calangome y la Liga de Mercaderes", Miscelánea Antropológica Ecuatoriana 6, Boletín de los Museos del Banco Central del Ecuador, Guayaquil, pp. 131-144.

Norton, Presley, et al., 1983, "Excavaciones en Salango, Provincia de Manabí”, Miscelánea Antropológica Ecuatoriana 3, Boletín de los Museos del Banco Central del Ecuador, Guayaquil, pp. 9-72.

Olsson, Axel A, 1961, Mollusks of the Eastern Pacific: Particularly from the Southern Half of the Panamic-Pacific Faunal Province (Panama to Perú), Paleontological Research Institution, Ithaca.

Paulsen, Allison C., 1974, "The Thorny Oyster and the Voice of God: Spondylus and Strombus in Andean Prehistory", American Antiquity 39 (4), Society of American Archaeology, 597-607.

Peterson, Christian E., 2006, 'Crafting'Hongshan Communities? Household Archaeology in the Chiefeng Region of Eastern Inner Mongolia, PRC. Tesis Doctoral, University of Pittsburgh, ProQuest/ UMI, Pittsburgh.

Peterson, Christian E. y Robert Drennan, 2005, “Communities, Settlements, Sites, and Surveys: Regional Scale-Analysis of Prehistoric Human Interaction", American Antiquity 70 (1), Society of American Archaeology, 5-30.

Piana Bruno, Luiz, y Hans Marotzke, 1997, Unidad Cultural en el Litoral Meridional Ecuatoriano, Escuela Superior Politécnica del Litoral, Guayaquil.

Pizarro, Francisco, 1844a, "Relación de los Primeros Descubrimientos de Francisco Pizarro y Diego de Almagro, (Original Manuscript 1527) en M. Fernández Navarrete, M. Salva, y P. Sainz de Baranda, eds., Colección de Documentos Inéditos Para la Historia de España, Volumen 5, Madrid, Imprenta de la Viuda de Calera, 193-201.

1844b, Relación del Descibrimiento y Conquista de los Reinos del Perú, y del Govierno y Orden que los Naturales Tenían " (Original Manuscript 1571)", en. Fernandez Navarrete, M. (eds)., Colección de Documentos Inéditos para la Historia de España, Volumen 5, Imprenta de la Viuda de Calera, Madrid, pp. 201-388.

Pillsbury, Joanne, 1996, "The Thorny Oyster and the Origins of Empire", Latin American Antiquity 7 (4), Society of American Archaeology, 313-340.

Reitz, Elizabeth J., y Maria Ann Masucci, 2004, Guangala Fishers and Farmers: A Case Study of Animal Use at El Azúcar, Southwestern Ecuador. University of Pittsburgh Memoirs in Latin American Archaeology 14, University of Pittsburgh Latin American Archaeology Publications, Pittsburgh.

Rudolf, Gloria, 1999, Panama's Poor: Victims, Agents, and History Makers, University Press of Florida, Gainesville.

Sahlins, Marshall, 1963, "Poor Man, Rich Man, Big Man, Chief: Political Types in Melanesia and Polynesia", Comparative Studies in Society and History 5 (3), Cambridge, Cambridge University Press, 285-303.

Sanders, William T., et al., 1979, The Basin of Mexico: Ecological Processes in the Evolution of a Civilization, Academic Press, New York.

Shimada, Izumi, 1994, Pampa Grande and the Mochica Culture, University of Texas Press, Austin.

Silva, María Isabel, 1984, Pescadores y Agricultores de la Costa Central del Ecuador: Un Modelo Socioeconómico de Asentamientos Precolombinos, Tesis de Maestría no publicada, University of Illinois Urbana-Champaign, Urbana-Champaign.

Smith, Michael E., 2004, "The Archaeology of Ancient State Economies", Annual Review of Anthropology 33, 73-102. 
Stemper, David., 1993, La persistencia de los cacicazgos prehispánicos en el río Daule, Costa del Ecuador, Pittsburgh/ Quito, Universidad de Pittsburgh Departamento de Antropología/ Ediciones Libri-Mundi.

Valdez, Francisco., 2006, "Drenajes, camellones y organización social: Usos del espacio y poder en La Tola, Esmeraldas", en: Valdez, Fernando (ed.), Agricultura Ancestral Camellones y Albarradas, Abya-Yala, Quito, pp. 189-223,

Vaughn, Kevin J., 2006, "Craft Production, Exchange, and Political Power in the Pre-Incaic Andes", Journal of Archaeological Research 14, University of New Mexico, Albuquerque, pp. 313-344.

Yépez, Alexandra, 2007, "La Dinámica de las Identidades: La Etnoarqueología como Instrumento del Pasado", en: García, Fernando (ed.), II Congreso Ecuatoriano de Antropología y Arqueología. Balance de la Última Década: Aporte, Retos y Nuevos Temas, Volumen 1, Abya-Yala, Quito, pp. 606-629.

Zeidler, James A., 1991, "Maritime Exchange in the Early Formative Period of Coastal Ecuador: Geopolitical Origins of Uneven Development", Research in Economic Anthropology 13, B. L. Isaac, Greenwich, JAL Press, 247-268.

Zvelebil, M., 1986, "Mesolithic Societies and the Transition to Farming: Problems of Time, Scale, and Organization", en: Zvelebil, M. (ed.), Hunters in Transition: Mesolithic Societies of Temperate Eurasia and their Transition to Farming, Cambridge, University Press, Cambridge, pp. 167-188.

Base de Datos de Arqueología de América Latina ubicada en la página http://www.pitt.edu/ laad/. 